\title{
Freeze-Thaw Performance and Moisture-Induced Damage Resistance of Base Course Stabilized with Slow Setting Bitumen Emulsion-Portland Cement Additives
}

\author{
Mojtaba Shojaei Baghini, ${ }^{1,2}$ and Amiruddin Ismail ${ }^{1,2}$ \\ ${ }^{1}$ Sustainable Urban Transport Research Centre (SUTRA), Faculty of Engineering and Built Environment, \\ Universiti Kebangsaan Malaysia, 43600 Bangi, Selangor, Malaysia \\ ${ }^{2}$ Department of Civil and Structural Engineering, Universiti Kebangsaan, Faculty of Engineering and Built Environment, \\ Universiti Kebangsaan Malaysia, 43600 Bangi, Selangor, Malaysia \\ Correspondence should be addressed to Mojtaba Shojaei Baghini; msbaghini@yahoo.com
}

Received 16 August 2015; Accepted 9 November 2015

Academic Editor: Charles C. Sorrell

Copyright (C) 2015 M. Shojaei Baghini and A. Ismail. This is an open access article distributed under the Creative Commons Attribution License, which permits unrestricted use, distribution, and reproduction in any medium, provided the original work is properly cited.

\begin{abstract}
Freeze-thaw (FT) cycles and moisture susceptibility are important factors influencing the geotechnical characteristics of soilaggregates. Given the lack of published information on the behavior of cement-bitumen emulsion-treated base (CBETB) under environmental conditions, especially freezing and thawing, this study investigated the effects of these additives on the CBETB performance. The primary goal was to evaluate the resistance of CBETB to moisture damage by performing FT, Marshall conditioning, and AASHTO T-283 tests and to evaluate the long-term stripping susceptibility of CBETB while also predicting the liquid antistripping additives to assess the mixture's durability and workability. Specimens were stabilized with Portland cement $(0 \%-6 \%)$, bitumen emulsion (0\%-5\%), and Portland cement-bitumen emulsion mixtures and cured for 7 days, and their shortand long-term performances were studied. Evaluation results of both the Marshall stability ratio and the tensile strength ratio show that the additions of additives increase the resistance of the mixtures to moisture damage. Results of durability tests performed for determining the resistance of compacted specimens to repeated FT cycles indicate that the specimen with the $4 \%$ cement$3 \%$ bitumen emulsion mixture significantly improves water absorption, volume changes, and weight losses. This indicates the effectiveness of this additive as a road base stabilizer with excellent engineering properties for cold regions.
\end{abstract}

\section{Introduction}

One of the important factors for maximizing pavement service life and minimizing pavement maintenance cost is the selection of a base with sufficient material resistance to damage under traffic loads and environmental conditions. Moisture susceptibility is a major catalyst for pavement damage, which plays a key role in the performance of the pavement. The geotechnical characteristics of soil-aggregates are considerably affected by different environmental conditions, especially freezing and thawing. Many studies have shown that freeze-thaw (FT) cycles decrease the soil-aggregate stability significantly [1-5]. Therefore, it is necessary to investigate the FT conditions from the viewpoint of the geotechnical application of soils in cold regions. When fine-grained soils are completely frozen, ice lenses form in the pores and the water volume increases by about $9 \%$, which causes cracks in the soils $[3,4,6,7]$. In cold regions, pavement engineers face the challenging task of establishing efficient methods/techniques for the modification of highway pavement materials under FT conditions. Soil-aggregate stabilization is considered one of these techniques aimed at improving the short-term and long-term performances and durability of the pavement structure. Parsons and Milburn (2003) and Baghini et al. (2015) have reported that, for many soil-aggregates, more than one stabilization agent may be effective and that financial considerations or availability may be the determining factor for their use [8-10]. In this 
context, cold-in-place stabilization is one of the most capable technologies for its technical reliability, cost-effectiveness, and low environmental impact [11-13]. Given the lack of previous studies on the durability of cold mixes of road base materials, cement-bitumen emulsion mixture was chosen as a nonconventional additive in the present study. Previous studies have indicated that the improvement of road base stabilization using cement-bitumen emulsion mixture is a function of the additive content, moisture content, dry density, $\mathrm{pH}$, and curing time $[9,11,14-16]$. On the basis of results of the unconfined compressive strength (UCS) test, indirect tensile strength (ITS) test, and indirect tension test for resilient modulus (ITRM), Baghini et al. (2015) recommended using a $4 \%$ cement-3\% bitumen emulsion as the optimum mixture in the pavement base layer. By evaluating the short-term performance of cement-bitumen emulsiontreated base (CBETB), they showed that the addition of a $4 \%$ cement-3\% bitumen emulsion mixture resulted in the UCS, ITS, and ITRM values increasing by $9 \%, 28 \%$, and $20 \%$, respectively, compared to the corresponding values of specimens with only $4 \%$ cement [14]. In addition, they showed that, after $12 \mathrm{WD}$ cycles, the addition of a $4 \%$ Portland cement-3\% bitumen emulsion mixture resulted in a reduction of $180 \%$ in water absorption, a volume change of $258 \%$, and a weight change of $212 \%$ relative to the values for specimens with only $4 \%$ cement. However, no previous studies have demonstrated the behavior of CBETB subjected to FT cycles in pavement construction and revealed the durability of CBETB under various environmental conditions and its moisture susceptibility. In addition, insufficient information is available on the moisture-induced damage of CBETB under various conditions of temperature and humidity. Hence, the primary objective of the present study was to evaluate the resistance of bitumen emulsion-treated base (BETB), cement-treated base (CTB), and CBETB to moisture damage by performing FT, Marshall conditioning, and AASHTO T-283 tests according to American Society for Testing and Materials (ASTM), American Association of State Highway and Transportation Officials (AASHTO), and British Standard (BS). Another objective of this study was to determine the optimum bitumen emulsion contents of BETB and CBETB by means of Marshall stability (MS), tensile strength, and maximum dry density (MDD) tests. The final aim was to evaluate the effects of cement and bitumen emulsion on the properties of CTB, BETB, and CBETB and to compare their effects on the performances of $\mathrm{CTB}, \mathrm{BETB}$, and CBETB.

\section{Experimental}

2.1. Materials. In this research, crushed granite aggregates acquired from Kajang Rock Quarry (Malaysia) were used as the base layer. Figure 1 indicates the grading curve of the soilaggregates within the limits specified by the ASTM standards for highways and/or airports due to ASTM D 448, ASTM D 1241, and ASTM D 2940.

It should be noted that a soil with a $\mathrm{pH}$ higher than 5.3 reacts normally with cement and lower than that is not suitable for stabilization with cement [17]. The general

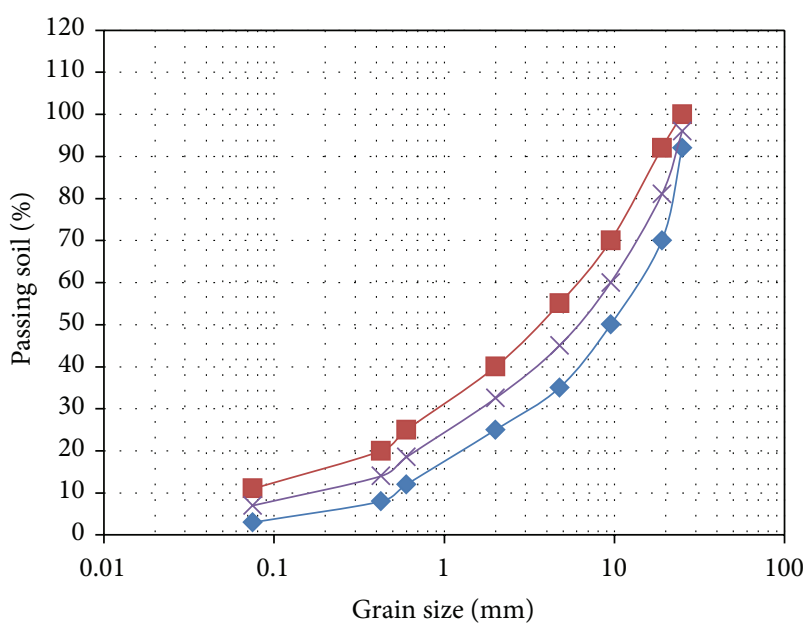

$\multimap$ Lower limit
$\rightarrow$ Upper limit
$\times$ Selected soil

FIGURE 1: Grading curves for soil-aggregates.

engineering properties of the soil-aggregates are summarized in Table 1 according to ASTM, AASHTO, and BS standards.

Type II Portland cement was used as a treatment material for the road base materials, because of its higher sulfate resistance, moderate heat of hydration, and mostly equivalent cost to other types of Portland cement. The components and properties of Portland cement are shown in Table 2 according to ASTM C 150 and ASTM C 114.

Cationic slow setting (CSS) emulsion is used in combination with aggregates with high surface area to provide the desired coating and curing behavior and higher effects on cement hydration. Tests on bitumen emulsion, test requirements, and tests results are presented in Table 3.

2.2. Sample Preparation. A review of the existing literature on CBETB indicates that the experimental results are strongly dependent on sample preparation, which is affected by moisture control and the mixing procedure as the critical factors [10, 18-21]. Baghini et al. [10] determined 3\% bitumen emulsion as the optimum content in CBETB on the basis of the UCS test, ITS test, and ITRM results. However, in the present research, the MS test was used to evaluate/confirm the optimum bitumen emulsion content as being $3 \%$. The specimens were prepared as follows. The required amount of Portland cement was added to the portion of soil passing the number 4 sieve ( $4.75 \mathrm{~mm}$, ASTM D 558) according to ASTM C 150 and ASTM C595. The mixture was mixed thoroughly to a uniform color, and, then, sufficient water (percent optimum mixture water minus percent emulsion water) was added and the soil-cement-water mixture was mixed again. After this preparation, the saturated, surfacedry aggregates (passing number $25 \mathrm{~mm}$ and retained on the number 4 sieve) were added to the mixture and mixed until they were thoroughly blended. Finally, bitumen emulsion with different contents $(5 \%-10 \%$ by weight of the total mixture) was added to the mixture in $1 \%$ increments at the 
TABLE 1: Properties of soil-aggregates used in this study.

\begin{tabular}{|c|c|c|c|}
\hline Property & Requirement & Test result & Test method \\
\hline Water content (\%) & NA & 6.621 & ASTM D 698 \\
\hline Unit weight $\left(\mathrm{g} / \mathrm{cm}^{3}\right)$ & NA & 2.19 & ASTM D 698 \\
\hline $\mathrm{pH}$ & $5.3-\min$ & 8.26 & ASTM D 4972 \\
\hline Unified classification & NA & GP-GM & ASTM D 2487 \\
\hline AASHTO classification & NA & A-1-a & ASTM D 3282/AASHTO M 145 \\
\hline Liquid limit (\%) & $25-\max$ & 21.4 & ASTM D 4318 \\
\hline Plastic limit (\%) & $29-\max$ & 19.6 & ASTM D 4318 \\
\hline Plastic index (\%) & $4-\max$ & 1.8 & ASTM D 4318 \\
\hline Coefficient of curvature (Cc) & NA & 2.39 & ASTM D 2487 \\
\hline Coefficient of uniformity $(\mathrm{Cu})$ & NA & 71.5 & ASTM D 2487 \\
\hline Group index & NA & 0 & ASTM D 3282 \\
\hline Specific gravity (OD) & NA & 2.659 & ASTM C 127/C 128 \\
\hline Specific gravity (SSD) & NA & 2.686 & ASTM C 127/C 128 \\
\hline Apparent specific gravity & NA & 2.731 & ASTM C 127/C 128 \\
\hline Water absorption (\%) & $2-\max$ & 0.973 & ASTM C 127/C 128 \\
\hline Linear shrinkage (\%) & $3-\max$ & 1.5 & BS 1377: Part 2 \\
\hline Elongation index (\%) & $25-\max$ & 13.03 & BS 812: Section 105.2 \\
\hline Flakiness index (\%) & $25-\max$ & 7.68 & BS 812: Section 105.1 \\
\hline Average least dimension ( $\mathrm{mm}$ ) & NA & 5.5 & BS 812: Section 105.1 \\
\hline Sand equivalent (\%) & $35-\min$ & 84 & ASTM D 2419 \\
\hline Los Angeles abrasion (\%) & $50-\max$ & 17.5 & ASTM C131 \\
\hline UCS (MPa) & NA & 0.25 & ASTM D 2166/D 1633 \\
\hline CBR (\%) & $80-\min$ & 101.32 & ASTM D 1883 \\
\hline
\end{tabular}

Table 2: Properties of Type II Portland cement.

\begin{tabular}{|c|c|c|c|}
\hline Components and properties & Requirement (\%) & Test result $(\%)$ & Test method \\
\hline Silicon dioxide $\left(\mathrm{SiO}_{2}\right)$ & $20-\min$ & 20.18 & ASTM C 150, C 114 \\
\hline Aluminum oxide $\left(\mathrm{Al}_{2} \mathrm{O}_{3}\right)$ & $6.0-\max$ & 5.23 & ASTM C 150, C 114 \\
\hline Calcium oxide $(\mathrm{CaO})$ & Not applicable & 64.40 & ASTM C 150, C 114 \\
\hline Ferric oxide $\left(\mathrm{Fe}_{2} \mathrm{O}_{3}\right)$ & $6.0-\max$ & 3.34 & ASTM C 150, C 114 \\
\hline Magnesium oxide $(\mathrm{MgO})$ & $6.0-\max$ & 1.80 & ASTM C 150, C 114 \\
\hline Sulfur trioxide $\left(\mathrm{SO}_{3}\right)$ & $6.0-\max$ & 3.03 & ASTM C 150, C 114 \\
\hline Loss on ignition & $3.0-\max$ & 2.17 & ASTM C 150, C 114 \\
\hline Insoluble residue & $0.75-\max$ & 0.18 & ASTM C 150, C 114 \\
\hline $\mathrm{Na}_{2} \mathrm{O}$ & Not applicable & 0.07 & ASTM C 150, C 114 \\
\hline $\mathrm{K}_{2} \mathrm{O}$ & Not applicable & 0.44 & ASTM C 150, C 114 \\
\hline Equivalent alkalies $\left(\mathrm{Na}_{2} \mathrm{O}+0.658 \mathrm{~K}_{2} \mathrm{O}\right)$ & $0.75-\max$ & 0.3595 & ASTM C 150, C 114 \\
\hline Tricalcium aluminate $\left(\mathrm{C}_{3} \mathrm{~A}\right)$ & $8-\max$ & 3.21 & ASTM C 150, C 114 \\
\hline Tricalcium silicate $\left(\mathrm{C}_{3} \mathrm{~S}\right)$ & Not applicable & 53.95 & ASTM C 150, C 114 \\
\hline Dicalcium silicate $\left(\mathrm{C}_{2} \mathrm{~S}\right)$ & Not applicable & 17.32 & ASTM C 150, C 114 \\
\hline Tetracalcium alumino-ferrite $\left(\mathrm{C}_{4} \mathrm{AF}\right)$ & Not applicable & 10.16 & ASTM C 150, C 114 \\
\hline Sum of $\left(\mathrm{C}_{3} \mathrm{~S}\right)$ and $\left(\mathrm{C}_{3} \mathrm{~A}\right)$ & $58-\max$ & 57.16 & ASTM C 150, C 114 \\
\hline Compressive strength, $\mathrm{MPa}$ & & & ASTM C 109/C 109M \\
\hline 3 days & $10-\min$ & 27.5 & \\
\hline 7 days & $17-\min$ & 40.3 & \\
\hline 28 days & $28-\min$ & 57.7 & \\
\hline Fineness, specific surface, $\mathrm{m}^{2} / \mathrm{kg}$ & & & ASTM C 204 \\
\hline Air permeability test & 280-Min & 338.1 & \\
\hline Autoclave expansion (soundness) & $0.8-\mathrm{Max}$ & 0.5 & ASTM C 151 \\
\hline
\end{tabular}


TABle 3: Properties of bitumen emulsion.

\begin{tabular}{|c|c|c|c|}
\hline Test on emulsions & Requirements & Test result & Test method \\
\hline Viscosity, Saybolt Furol at $25^{\circ} \mathrm{C}$ & $20-100$ & 20.9 & ASTM D 2397 \\
\hline Storage stability test, $24 \mathrm{~h}, \%$ & 1 & 0.22 & ASTM D 2397 \\
\hline Particle charge test & Positive & Positive & ASTM D 2397 \\
\hline Sieve test, \% & $0.1 \max$ & 0.0 & ASTM D 2397 \\
\hline Cement mixing test, $\%$ & $2 \max$ & 0.23 & ASTM D 2397 \\
\hline Oil distillate, by volume of emulsion, $\%$ & $3 \max$ & 1.5 & ASTM D 2397 \\
\hline Residue from distillation, $\%$ & $57 \mathrm{~min}$ & 61.75 & ASTM D 2397 \\
\hline Penetration, $25^{\circ} \mathrm{C}, 100 \mathrm{~g}, 5 \mathrm{~s}, 0.1 \mathrm{~mm}$ & $100-250$ & 109.2 & ASTM D 2397 \\
\hline Solubility in trichloroethylene, $\%$ & $97.5 \mathrm{~min}$ & 99.8 & ASTM D 2397 \\
\hline Water content & NA & 58.3 & ASTM D 2397 \\
\hline
\end{tabular}

TABLE 4: MDD and OMC of CTB, CBETB, and mixture without additives.

\begin{tabular}{|c|c|c|c|c|c|c|c|c|c|c|c|c|c|}
\hline \multirow{3}{*}{ Parameter } & \multicolumn{13}{|c|}{ Additives content } \\
\hline & \multicolumn{8}{|c|}{ Cement (\%) } & \multicolumn{5}{|c|}{$4 \%$ cement-bitumen emulsion (\%) } \\
\hline & 0 & 1 & 2 & 3 & 4 & 5 & 6 & 1 & 2 & 3 & 4 & 5 & 6 \\
\hline MDD & 2.190 & 2.206 & 2.236 & 2.273 & 2.287 & 2.290 & 2.296 & 2.292 & 2.321 & 2.341 & 2.337 & 2.291 & 2.274 \\
\hline OMC & 6.621 & 7.550 & 8.197 & 8.545 & 8.927 & 9.310 & 9.773 & 8.347 & 7.767 & 7.187 & 6.607 & 6.027 & 5.447 \\
\hline
\end{tabular}

time of compaction, and the mixture was mixed until a uniform distribution of additives was achieved. The mixtures were formed by immediately compacting them in a mold depending on the test method, which are explained in detail in Section 2.3. The compacted specimens were cured in the mold for $12 \mathrm{~h}$ at room temperature; subsequently, they were extruded and allowed to air-cure for a specific time period at $25^{\circ} \mathrm{C}$ according to ASTM D 1632. The MDD and optimum moisture content (OMC) of CTB with different cement contents $(0 \%-6 \%)$ and of CBETB with a mixture of $4 \%$ cement and bitumen emulsion of various contents $(0 \%-$ $5 \%$ ) were determined according to ASTM D 558 method B, and those for the mixture without additive were determined according to ASTM D 698 method C. The obtained results are presented in Table 4, which indicate that the highest value of MDD was obtained for the $4 \%$ cement-3\% bitumen emulsion mixture. In addition, it can be seen from the table that both the MDD and the OMC increased with increasing cement content. For CTB, the OMC increased by about $0.25 \%$ per percentage increase in the cement content.

\subsection{Test Methods}

2.3.1. MS. MS is the maximum resistance load obtained at a constant rate of deformation loading. In this study, the objectives of the MS test were to clarify the effects of cement, bitumen emulsion, and a combination of cement and bitumen emulsion on the moisture damage (AASHTO T-283 and ASTM D 4867) and strength (ASTM D 1559 and ASTM D 6927) of BETB, CTB, and CBETB and to determine the optimum bitumen emulsion content. The samples were compacted in a cylindrical mold $101.60 \mathrm{~mm}$ in diameter and $63 \mathrm{~mm}$ in height according to ASTM D 6927. A total of 54 samples-18 samples with cement (0\%-6\%), 18 samples with bitumen emulsion (5\%-10\%), and 18 samples with the $4 \%$ cement-bitumen emulsion (5\%-10\%) mixture-were prepared and cured for 7 days. In accordance with the stability test, the specimens were submerged in a water bath at a temperature of $60^{\circ} \mathrm{C}$ for $30 \mathrm{~min}$. The average MS of the 7day-cured specimens was determine using the MS testing machine by applying a load at a constant deformation loading rate of $50 \mathrm{~mm} / \mathrm{min}$ until the peak load was reached.

\subsubsection{Resistance of Mixtures to Moisture-Induced Damage.} Many studies have revealed that the primary factor affecting road base performance is moisture damage [22-24]. Water in the pavement structure usually causes a decrease in the strength and stiffness of most engineering materials. This water may originate from surface penetration, high groundwater levels, capillary rise, frost effects, or lateral flow. Soils and aggregates that are at or near saturation develop excess pore water pressure under traffic loading, thereby reducing their shear strength and shortening the service life of welldesigned and well-constructed pavements. Moisture damage can increase the life cycle cost of pavements significantly owing to the resultant high maintenance costs in both the short term and the long term. In this study, the resistance of $\mathrm{BETB}, \mathrm{CTB}$, and CBETB to moisture damage was investigated by Marshall conditioning and AASHTO T-283 tests. It should be noted that there are no acceptable standards for the minimum Marshall stability ratio (MSR) and tensile strength ratio (TSR). A TSR of 0.8 or more has been typically applied as a minimum acceptable value for mixtures that are relatively resistant to moisture damage.

(1) Marshall Conditioning Test. A total of 18 samples-6 samples with $4 \%$ cement, 6 samples with $3 \%$ bitumen emulsion, and 6 samples with the $4 \%$ cement-3\% bitumen emulsion mixture-were prepared and cured for 7 days. The specimens were divided into two groups: the first group (namely, unconditioned samples) of 9 specimens was submerged in a water bath at $60^{\circ} \mathrm{C}$ for $30 \mathrm{~min}$, and, then, the average MS values were 
obtained by loading at a deformation rate of $50 \mathrm{~mm} / \mathrm{min}$. The second group (namely, conditioned samples) of 9 specimens was submerged in a water bath at $60^{\circ} \mathrm{C}$ for $24 \mathrm{~h}$, and, then, the average MS values were obtained by loading at the same deformation loading rate. Finally, the MSR was calculated by the following equation: $\mathrm{MSR}=\left(\mathrm{MSR}_{\mathrm{con}} / \mathrm{MSR}_{\text {uncon }}\right) \times 100$, where MSR is the Marshall stability ratio, $\mathrm{MSR}_{\text {con }}$ is the conditioned MS, and $\mathrm{MSR}_{\text {uncon }}$ is the unconditioned MS. The MSR can be used to evaluate the moisture susceptibility of $\mathrm{BETB}, \mathrm{CTB}$, and CBETB as a criterion for identifying the resistance of these mixtures to moisture damage.

(2) AASHTO T-283 Test. This test method is used for evaluating the long-term stripping susceptibility of a mixture and predicting the liquid antistripping additives that can be added to the soil-aggregates and subsequently evaluating the effectiveness of these additives. Three specimens for each additive were chosen as control specimens and were tested without moisture conditioning; three more specimens were chosen to be conditioned by vacuum saturation with water and a subsequent cycle of freezing and warm water soaking. A total of 18 cylindrical specimens with a size of $63 \mathrm{~mm} \times$ $101.60 \mathrm{~mm}$ (diameter) were prepared and divided into two groups. Preconditioning of the specimens was performed by applying vacuum saturation of $28 \mathrm{~mm} \mathrm{Hg}$ for a period of $5 \mathrm{~min}$ to ensure that the specimens have at least $2.5 \mathrm{~mm}$ of water above their surface. It should be noted that the degree of saturation should be between $55 \%$ and $80 \%$; if the degree is any lower, the vacuum procedure is repeated using more vacuum and/or time. The saturated surface-dry specimens were covered tightly with plastic bags and placed in a freezer at $-18^{\circ} \mathrm{C}$ for $16 \mathrm{~h}$. The specimens were then submerged in a water bath at $60^{\circ} \mathrm{C}$ for $24 \mathrm{~h}$; subsequently, they were submerged in a water bath at $25^{\circ} \mathrm{C}$ for $2 \mathrm{~h}$. The specimens were then removed and tested at $25^{\circ} \mathrm{C}$ under indirect tension at the constant movement rate of $50 \mathrm{~mm} / \mathrm{min}$ of the testing machine in order to determine the ITS. The indirect TSR was calculated by the following equation: TSR = $\left(\mathrm{TSR}_{\text {con }} / \mathrm{TSR}_{\text {uncon }}\right) \times 100$, where TSR is the ITS ratio, $\mathrm{TSR}_{\text {con }}$ is the conditioned tensile strength, and $\mathrm{MSR}_{\text {uncon }}$ is the unconditioned tensile strength.

2.3.3. Freezing and Thawing. Durability to FT cycles is one of the major concerns for road materials in seasonal areas and countries with cold regions experiencing low temperatures. The FT test is a significantly effective test for cold regions. The results of this test provide useful data on frost heave potential, swelling and shrinkage potential, thaw weakening, and influence of FT cycles on the road pavement performance. FT tests have several applications depending on the cycles, temperatures, additives, and road materials. Daniels et al. [25] evaluated the durability of polymer-modified Boston blue clay by subjecting it to five FT cycles, which revealed an increase in the hydraulic conductivity of the mixture. Yıldız and Soğanc [7] investigated the influence of FT on the permeability of lime-modified Aksaray clay and Doganhisar clay after five FT cycles. Pospíchal et al. [26] evaluated the effect of periodic freezing and thawing on the properties of lightweight concrete after 25 FT cycles.
Kucharczyková et al. [27] studied the effects of porous aggregate on the FT resistance of lightweight concrete after 25 FT cycles. Bin-Shafique et al. [28] conducted an experimental study to evaluate the long-term performance of two flyash-stabilized fine-grained soil subbases subjected to 12 FT cycles. Liu et al. [29] investigated the long-term performance of modified soils with cement and lime according to their behaviors after 12 FT cycles. In a study by Wong and Haug [5], specimens were subjected to freezing at $-20^{\circ} \mathrm{C}$ for $6 \mathrm{~h}$ and subsequent thawing at $25^{\circ} \mathrm{C}$. Alkire and Jashimuddin [30] subjected specimens to freezing at $-30^{\circ} \mathrm{C}$ for $24 \mathrm{~h}$ and subsequently to thawing at $25^{\circ} \mathrm{C}$. Simonsen and Isacsson [31] performed tests at various temperatures from $20^{\circ} \mathrm{C}$ to $-10^{\circ} \mathrm{C}$ during only one FT cycle. Hazirbaba and Gullu [32] performed FT tests to investigate the effects of FT cycles on the performance and strength of fine-grain soils stabilized with geofiber and synthetic fluid under freezing at $-20^{\circ} \mathrm{C}$ of $24 \mathrm{~h}$ and subsequent thawing at $21^{\circ} \mathrm{C}$ for $24 \mathrm{~h}$. Ghazavi and Roustaei [1] studied the performance of soil-aggregate reinforced with geotextile by subjecting them to a total of nine FT cycles at $-20^{\circ} \mathrm{C}$ for $6 \mathrm{~h}$ (freezing) and at $20^{\circ} \mathrm{C}$ for $6 \mathrm{~h}$ (thawing). Qi et al. [3] and Altun et al. [2] investigated the improvement of a soil-aggregate treated with cement and untreated soil-aggregate by using seven FT cycles and one FT cycle, respectively. However, given the lack of published information on the behavior of base course materials stabilized with cement-bitumen emulsion mixture under FT conditions, the present study investigated the effects of these additives on the performance of CBETB. In this study, the resistances of BETB, CTB, and CBETB to repeated FT cycles were evaluated by adopting the ASTM D 560 method B standard, with the aim of achieving a degree of hardness that would be sufficient to resist field weathering. The steps for determining moisture changes, volume changes, and weight losses as specified by the test method were followed while subjecting the hardened specimens to repeated FT cycles. The specimens were compacted with different additives in a cylindrical mold with dimensions of $101.60 \mathrm{~mm}$ (diameter) $\times 116.4 \mathrm{~mm}$ (height) to achieve the MDD at the OMC by using the compaction procedure specified in ASTM D 558, as described in Section 2.2. To acquire data for calculating the FT test parameters (moisture changes, volume changes, and weight losses), the 7-day-cured specimens were weighed and measured (i.e., the average diameter and height were determined) at the end of the curing process. The specimens were then placed in a freezing cabinet having a temperature of $-23^{\circ} \mathrm{C}$ for $24 \mathrm{~h}$, after which they were removed and weighed and measured again. Following the specified freezing period, the specimens were placed in a moist room at $21^{\circ} \mathrm{C}$ for $23 \mathrm{~h}$ under a relative humidity of $100 \%$ in order to thaw them; subsequently, they were removed, weighed, and measured. They were then subjected to two firm strokes with a wire scratch brush over their entire areas (20 and 4 brush strokes were performed for the sides and each end, resp.); subsequently, they were again weighed, measured, and finally replaced in the freezing cabinet to repeat the entire process for 12 cycles, where each cycle lasted for $48 \mathrm{~h}$. The volume changes of BETB, CTB, and CBETB were determined by calculating the difference between the volumes of the specimens at the time 


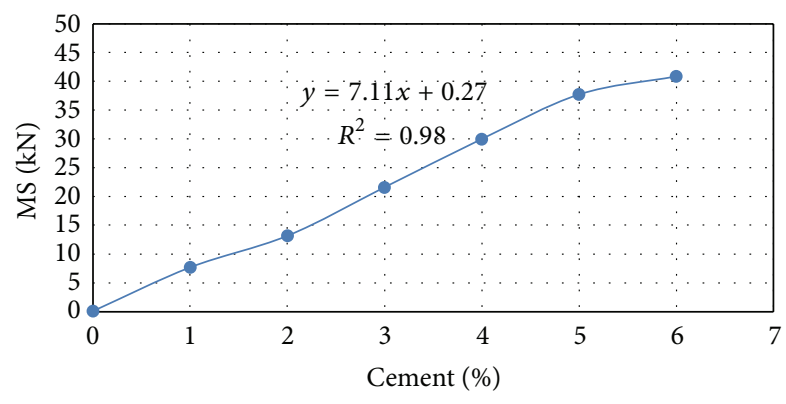

FIGURE 2: Influence of cement content on MS of CTB.

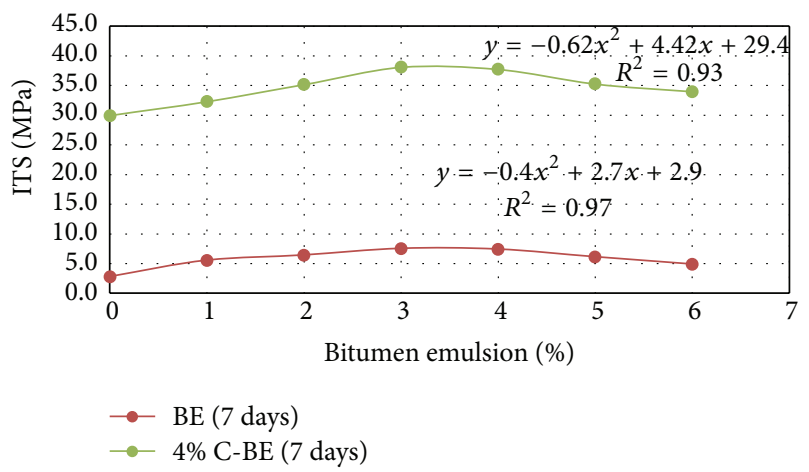

FIGURE 3: Influence of bitumen emulsion content on MS of BETB and CBETB. Here, "C" denotes cement and "BE" denotes bitumen emulsion.

of molding and the subsequent volumes as a percentage of the original volume. The weight losses of the specimens of the mixtures were determined as a percentage of the final ovendry weight and original oven-dry weight.

\section{Results and Discussion}

3.1. Results of MS Tests. The results of the MS tests are shown in Figures 2 and 3. Specifically, Figure 2 shows the effect of the cement content on the MS of CTB for 7 days of curing, as obtained using a linear model on the basis of experimental data. From the figure, it can be seen that the MS values increased with increasing content of the Portland cement; this trend is attributed to the hydration products of the Portland cement-water mixture, which fill the pore space between the grains of the matrix and then cause an increase in the rigidity of its structure by forming a large number of rigid bonds in the mixture [10]. Figure 3 shows the effect of the bitumen emulsion content on the MS values of BETB and CBETB for 7 days of curing, as obtained using two nonlinear models. The results indicate that an increase in the bitumen emulsion content causes an increase of up to $3 \%$ in the MS value. However, at contents higher than 3\%, the MS value decreases because of the higher water content (58.3\%) of bitumen emulsion, which prevents the occurrence of sufficient compaction and decreases the dry unit weight of the mixture. The specimen with the $4 \%$ cement- $3 \%$ bitumen emulsion mixture had $127 \%$ and 508\% improved MS values

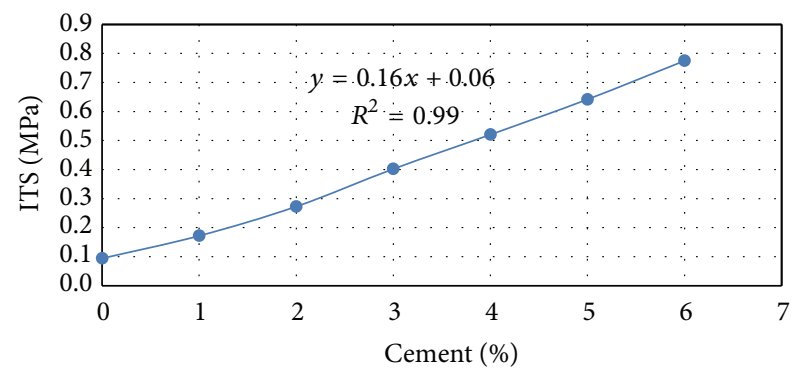

FIGURE 4: Influence of cement content on ITS of CTB.

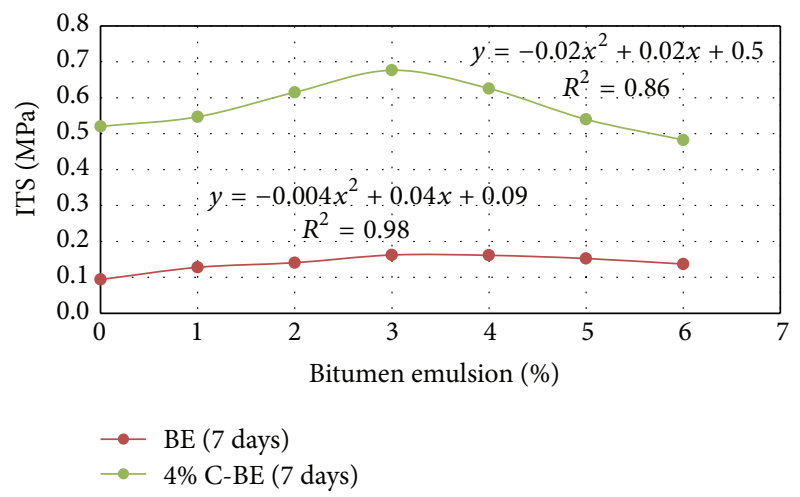

FIGURE 5: Influence of bitumen emulsion content on ITSs of BETB and CBETB.

compared to the specimens with $4 \%$ cement and 3\% bitumen emulsion, respectively.

3.2. Results of ITS Tests. ITS is used to determine the tensile strengths of BETB, CTB, and CBETB, which may be related to the cracking properties of the pavement structure. Marshall specimens and Marshall apparatus were used to determine the ITS values. The specimens were prepared and classified in the same manner as that mentioned in Section 2.2. A total of 54 samples were prepared: 18 samples with cement $(0 \%-6 \%), 18$ samples with bitumen emulsion $(0 \%-6 \%)$, and 18 samples with the $4 \%$ cement-bitumen emulsion $(0 \%-$ $6 \%)$ mixture. The cylindrical specimens were loaded with a vertical static compressive load at the deformation rate of $50 \mathrm{~mm} / \mathrm{min}$ under indirect tension at $25^{\circ} \mathrm{C}$. The ITS values were determined at the failure load according to the equation $S_{t}=(2 \times P) /(\pi \times t \times D)$, where $S_{t}$ is the tensile strength [MPa], $P$ is the optimum load [N], $t$ is the thickness of the specimens $[\mathrm{mm}]$, and $D$ is the diameter of the specimens [mm]. In this study, the ITS was used as a control according to AASHTO T-283. The results of the ITS tests are shown in Figures 4 and 5.

Specifically, Figure 4 shows the average ITS values of $\mathrm{CTB}$ as a function of the cement content percentage. It can be seen that the use of cement resulted in a significant improvement in the ITS value. The tensile strength increased with increasing cement content, which indicates that CTB appears to be capable of withstanding larger tensile stress prior to cracking. Figure 5 shows the ITS values of BETB 
TABLE 5: Results of MSR of conditioned and unconditioned specimens.

\begin{tabular}{|c|c|c|c|}
\hline \multirow{2}{*}{ Type of additive } & \multicolumn{2}{|c|}{ MS (kN) } & \multirow{2}{*}{ MSR } \\
\hline & $\mathrm{MS}_{\mathrm{con}}(\mathrm{kN})$ & $\mathrm{MS}_{\text {uncon }}(\mathrm{kN})$ & \\
\hline $4 \% \mathrm{C}$ & 31.56 & 29.95 & 1.06 \\
\hline $3 \% \mathrm{BE}$ & 6.15 & 7.52 & 0.81 \\
\hline $4 \% \mathrm{C}-3 \% \mathrm{BE}$ & 41.43 & 38.2 & 1.09 \\
\hline
\end{tabular}

TABLE 6: Results of TSR of conditioned and unconditioned specimens.

\begin{tabular}{lcccc}
\hline $\begin{array}{l}\text { Type of } \\
\text { additive }\end{array}$ & $\begin{array}{c}\text { Degree of } \\
\text { saturation }(\%)\end{array}$ & \multicolumn{2}{c}{ ITS $(\mathrm{MPa})$} & TSR \\
\hline $4 \% \mathrm{C}$ & 0.70 & 0.58 & 0.52 & 1.12 \\
$3 \% \mathrm{BE}$ & 0.73 & 0.13 & 0.16 & 0.82 \\
$4 \% \mathrm{C}-3 \% \mathrm{BE}$ & 0.75 & 0.79 & 0.68 & 1.16 \\
\hline
\end{tabular}

and CBETB. The results indicate that an increase in the bitumen emulsion content causes an increase of up to $3 \%$ in the ITS value; however, at a content higher than $3 \%$, the ITS value decreases. The mechanism of this decrease has been described in Section 3.1. The results indicate that the bitumen emulsion additive of CBETB results in a significant increase in the ITS. The specimen with the $4 \%$ cement- $3 \%$ bitumen emulsion mixture has $134 \%$ and $419 \%$ improved ITS values compared to the specimens with $4 \%$ cement and $3 \%$ bitumen emulsion, respectively.

3.3. Results of MSR and TSR Evaluations. Resistance of CTB, BETB, and CBETB to moisture damage was evaluated using the MSR and TSR values. The indexes of MSR and TSR are used to measure the moisture susceptibility of mixtures. The ratio of strengths of conditioned samples to those of unconditioned samples is a criterion for determining the moisture susceptibility of CTB, BETB, and CBETB. Figure 6 and Table 5, respectively, present the MS and MSR values of CTB, BETB, and CBETB for the conditioned and unconditioned specimens. Further, Figure 7 and Table 6, respectively, present the ITS and TSR values of CTB, BETB, and CBETB for the conditioned and unconditioned specimens. Figure 8 also shows the MSR and TSR. It is clearly seen that the highest retained stability (MSR) and TSR values (1.09 and 1.16, resp.) were observed for the specimen with the $4 \%$ cement-3\% bitumen emulsion mixture. This result could be attributed to the significant role of bitumen emulsion in improving the adhesion of CBETB when mixed with cement, which in turn increases the resistance of CBETB to moisture damage and improves its stability. This implies that introducing Portland cement and bitumen emulsion into soil-aggregate mixtures reduces their moisture susceptibility because both these components are effective adhesive agents for mixtures.

3.4. Results of FT Tests. In this study, the BETB, CTB, and CBETB specimens were subjected to the FT tests, according to the procedure and test method explained in Section 2. The influence of FT on the specimens was evaluated by examining

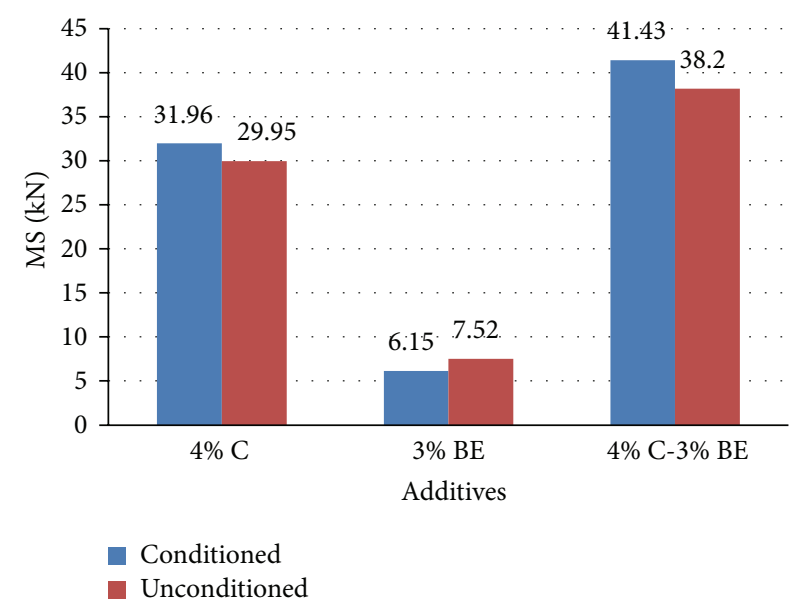

FIGURE 6: MS values of conditioned and unconditioned specimens.

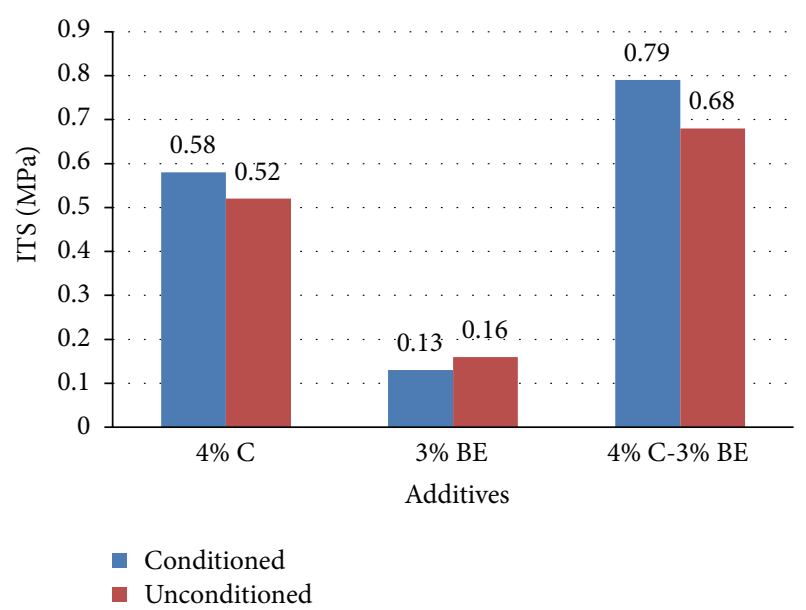

FIGURE 7: ITS values of conditioned and unconditioned specimens.

their performance under $12 \mathrm{FT}$ cycles. The results of the FT tests are shown in Figures 9-13. Specifically, Figures 911 show the results of moisture changes, volume changes, and weight losses of the soil aggregate treated with bitumen emulsion, cement, and a cement-bitumen emulsion mixture, respectively, under 12 FT cycles, with the aim of evaluating the resistance of the specimens to repeated FT cycles. From these figures, it can be seen that the average water absorptions of the specimens treated with cement, bitumen emulsion, and the cement-bitumen emulsion mixture are $3.65 \%, 4.55 \%$, and $2.92 \%$, respectively, for each FT cycle. These results show that the specimen with the $4 \%$ cement- $3 \%$ bitumen emulsion mixture has $125 \%$ and $155.8 \%$ improved water absorption compared to the specimens with $4 \%$ cement and $3 \%$ bitumen emulsion, respectively. In addition, the average volume changes of the specimens treated with cement, bitumen emulsion, and the cement- $3 \%$ bitumen emulsion mixture are $0.354 \%, 2.53 \%$, and $0.212 \%$, respectively, for each FT cycle. These results indicate that the specimen with the $4 \%$ cement$3 \%$ bitumen emulsion mixture has $167 \%$ and $788 \%$ improved volume changes compared to the specimens with $4 \%$ cement and $3 \%$ bitumen emulsion, respectively. Finally, the average 


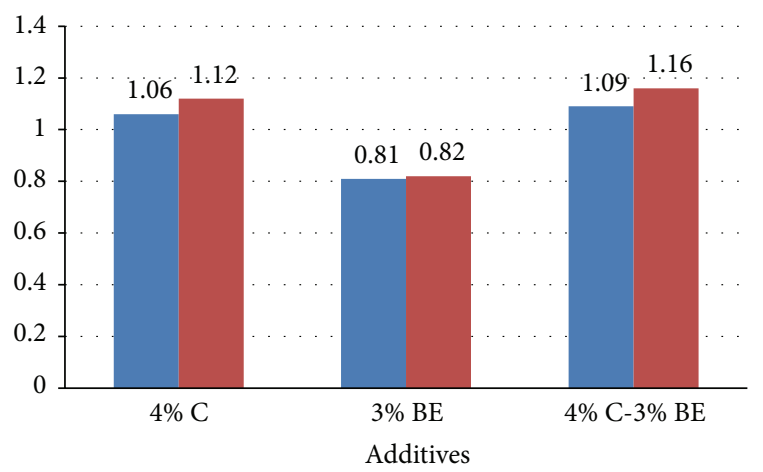

- MSR

- TSR

FIGURE 8: Results of MSR and TSR for various additives.

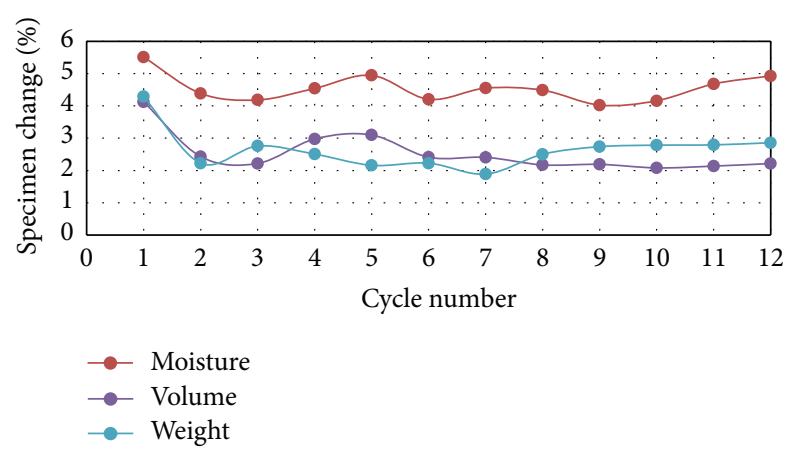

Figure 9: Moisture, volume, and weight changes of BETB.

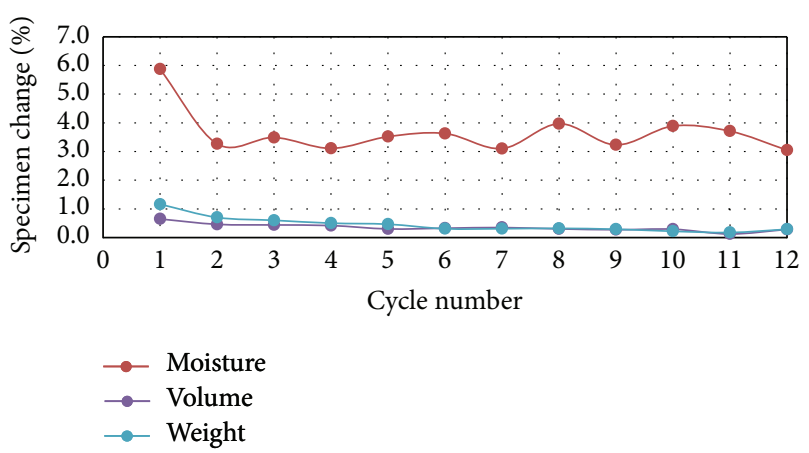

Figure 10: Moisture, volume, and weight changes of CTB.

weight losses of the specimens treated with cement, bitumen emulsion, and the cement-3\% bitumen emulsion mixture are $0.443 \%, 2.64 \%$, and $0.246 \%$, respectively, for each FT cycle. These results demonstrate that the specimen with the $4 \%$ cement-3\% bitumen emulsion mixture has $180 \%$ and $1070 \%$ improved weight losses compared to the specimens with $4 \%$ cement and $3 \%$ bitumen emulsion, respectively.

Figures 12 and 13 show the results of the total weight losses and total volume changes of the BETB, CTB, and CBETB specimens induced by subjecting hardened specimens to 12 FT cycles. From the figures, it is clear that the total weight losses of the specimens treated with cement, bitumen emulsion, and the cement-bitumen emulsion mixture were

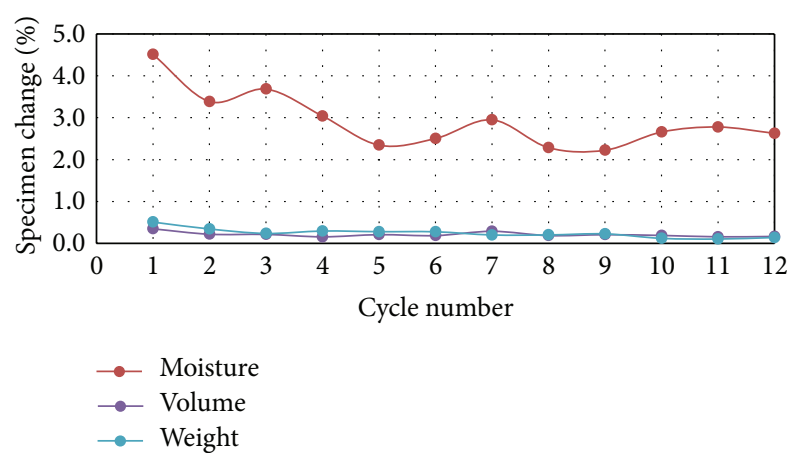

FIGURE 11: Moisture, volume, and weight changes of CBETB.

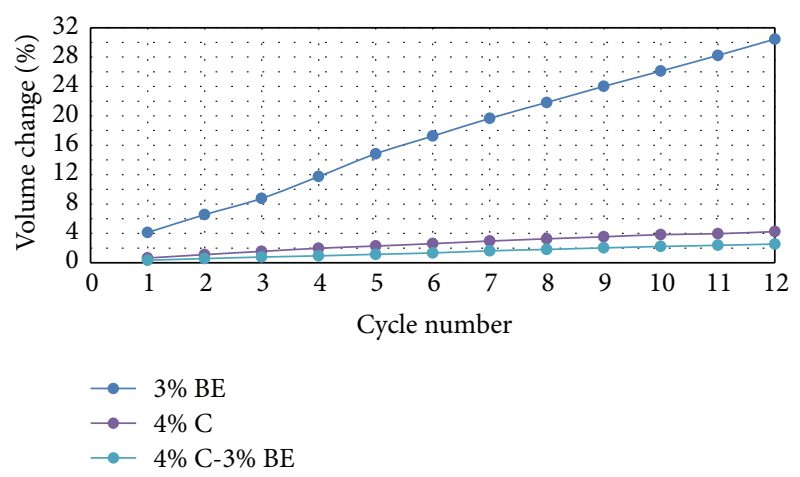

Figure 12: Total volume changes of BETB, CTB, and CBETB.

$5.363 \%, 31.71 \%$, and $2.95 \%$, respectively, and that their total volume changes were $4.245 \%, 30.44 \%$, and $2.54 \%$, respectively, after 12 FT cycles. These results demonstrate that the specimen treated with the $4 \%$ cement- $3 \%$ bitumen emulsion mixture had $180 \%$ and $1070 \%$ improved weight losses and $167 \%$ and $1198 \%$ improved volume changes compared to the specimens with $4 \%$ cement and 3\% bitumen emulsion, respectively. These results clearly indicate that cementbitumen emulsion mixtures are effective adhesive agents for improving the durability and workability of mixtures.

\section{Conclusions}

In this work, an extensive experimental study was conducted for evaluating the improvement in the moisture damage and FT performances of base course materials stabilized with conventional (cement) and nonconventional (bitumen emulsion, a novel additive) additives and a mixture of these two additives. The short-term performances of BETB, $\mathrm{CTB}$, and CBETB were investigated via ITS and MS tests, and their long-term performances were investigated under various environmental conditions such as wetting (Marshall conditioning and AASHTO T-283 tests), freezing (AASHTO T-283 and FT tests), and thawing (FT test). The findings of this study indicate that application of the cement-bitumen emulsion mixture to road bases is an effective treatment for significantly improving its moisture damage performance, 


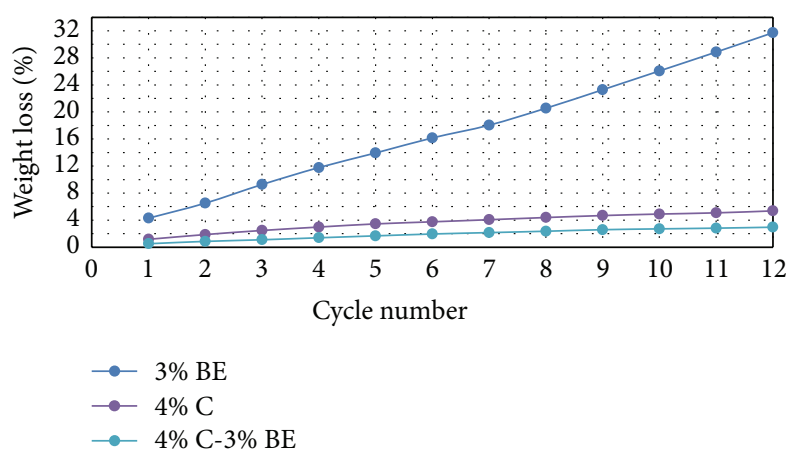

Figure 13: Total weight losses of BETB, CTB, and CBETB.

weight loss, volume changes, and strength. The key conclusions drawn from the analysis results of this study are as follows.

(i) The results of MS and ITS tests show that the addition of the cement-bitumen emulsion mixture effectively increases the Marshall stability and tensile strength of the base.

(ii) The MS and ITS values of the specimen treated with the $4 \%$ cement- $3 \%$ bitumen emulsion mixture were $42.6 \%$ and $53.82 \%$ improved compared to those of the specimen treated with $4 \%$ cement and $495.6 \%$ and $400 \%$ improved compared to those of the specimen treated with $3 \%$ bitumen emulsion, respectively.

(iii) Results of both the MSR and the TSR evaluations show that the additions of the additives increase the resistance of BETB, CTB, and CBETB to moisture damage. However, CBETB has higher values of the MSR and TSR, that is, 1.07 and 1.27, respectively, which implies that incorporating the cement-bitumen emulsion mixture in road bases would reduce their moisture susceptibility.

(iv) On the basis of the study results, the recommended optimum content of bitumen emulsion is $3 \%$.

(v) The results of the durability test (FT cycles) performed for determining the resistance of the compacted specimens to repeated FT processes revealed that the specimen treated with the $4 \%$ cement- $3 \%$ bitumen emulsion mixture has $370.5 \%, 333.93 \%$, and $267.3 \%$ improved water absorption, volume changes, and weight losses, respectively, compared to the specimen treated with $4 \%$ cement.

(vi) The results of the FT test showed that the total weight losses and volume changes of the specimen treated with the $4 \%$ cement- $3 \%$ bitumen emulsion mixture are less than $2 \%$ after 12 repeated FT cycles; this indicates the effectiveness of this additive as a road base stabilizer owing to its outstanding engineering properties for cold regions, as well as its effectiveness in improving the durability and workability of road bases.

\section{Conflict of Interests}

The authors declare that they have no conflict of interests.

\section{Acknowledgments}

The authors would like to thank the Sustainable Urban Transport Research Centre (SUTRA) at the Faculty of Engineering and Built Environment of Universiti Kebangsaan Malaysia (UKM) for providing research facilities. The authors also would like to acknowledge UKM for providing research funding through Project DLP-2014-010.

\section{References}

[1] M. Ghazavi and M. Roustaei, "Freeze-thaw performance of clayey soil reinforced with geotextile layer," Cold Regions Science and Technology, vol. 89, pp. 22-29, 2013.

[2] S. Altun, A. Sezer, and A. Erol, "The effects of additives and curing conditions on the mechanical behavior of a silty soil," Cold Regions Science and Technology, vol. 56, no. 2-3, pp. 135140, 2009.

[3] J. Qi, W. Ma, and C. Song, "Influence of freeze-thaw on engineering properties of a silty soil," Cold Regions Science and Technology, vol. 53, no. 3, pp. 397-404, 2008.

[4] J. Qi, P. A. Vermeer, and G. Cheng, "A review of the influence of freeze-thaw cycles on soil geotechnical properties," Permafrost and Periglacial Processes, vol. 17, no. 3, pp. 245-252, 2006.

[5] L. C. Wong and M. D. Haug, "Cyclical closed-system freezethaw permeability testing of soil liner and cover materials," Canadian Geotechnical Journal, vol. 28, no. 6, pp. 784-793, 1991.

[6] H. Gullu and K. Hazirbaba, "Unconfined compressive strength and post-freeze-thaw behavior of fine-grained soils treated with geofiber and synthetic fluid," Cold Regions Science and Technology, vol. 62, no. 2-3, pp. 142-150, 2010.

[7] M. Ylldız and A. S. Soğanc, "Effect of freezing and thawing on strength and permeability of lime-stabilized clays," Scientia Iranica, vol. 19, no. 4, pp. 1013-1017, 2012.

[8] R. L. Parsons and J. P. Milburn, "Engineering behavior of stabilized soils," Transportation Research Record, vol. 1837, no. 1, pp. 20-29, 2003.

[9] M. S. Baghini, A. Ismail, and M. R. Bin Karim, "Evaluation of cement-treated mixtures with slow setting bitumen emulsion as base course material for road pavements," Construction and Building Materials, vol. 94, pp. 323-336, 2015.

[10] M. S. Baghini, A. Ismail, M. R. Karim, F. Shokri, and A. A. Firoozi, "Effect of styrene-butadiene copolymer latex on properties and durability of road base stabilized with Portland cement additive," Construction and Building Materials, vol. 68, pp. 740-749, 2014.

[11] D. R. Salomon, Asphalt Emulsion Technology: Transportation Research Circular E-C102, Transportation Research Board, Characteristics of Bituminous Materials Committee, Washington, DC, USA, 2006.

[12] S. Brown and D. Needham, "A study of cement modified bitumen emulsion mixtures," Association of Asphalt Paving Technologists, vol. 69, no. 1, pp. 92-121, 2000.

[13] F. Wang, Y. Liu, and S. Hu, "Effect of early cement hydration on the chemical stability of asphalt emulsion," Construction and Building Materials, vol. 42, pp. 146-151, 2013. 
[14] M. S. Baghini, A. B. Ismail, M. R. Karim, F. Shokri, and A. A. Firoozi, "Effects on engineering properties of cement-treated road base with slow setting bitumen emulsion," International Journal of Pavement Engineering, vol. 16, pp. 1-14, 2015.

[15] D. Lesueur and J. J. Potti, "Cold mix design: a rational approach based on the current understanding of the breaking of bituminous emulsions," Road Materials and Pavement Design, vol. 5, supplement 1, pp. 65-87, 2004.

[16] W. G. Wong, Y. Qun, and K. C. P. Wang, "Performances of asphalt-treated base and semi-rigid base," HKIE Transactions, vol. 10, no. 3, pp. 54-58, 2003.

[17] ACI Committee, "State-of-the-art report on soil cement," ACI Materials Journal, vol. 87, no. 4, pp. 395-417, 1997.

[18] R. Wang, P.-M. Wang, and X.-G. Li, "Physical and mechanical properties of styrene-butadiene rubber emulsion modified cement mortars," Cement and Concrete Research, vol. 35, no. 5, pp. 900-906, 2005.

[19] J. A. Rossignolo and M. V. C. Agnesini, "Durability of polymermodified lightweight aggregate concrete," Cement and Concrete Composites, vol. 26, no. 4, pp. 375-380, 2004.

[20] Y. Ohama, "Polymer-based materials for repair and improved durability: Japanese experience," Construction and Building Materials, vol. 10, no. 1, pp. 77-82, 1996.

[21] G. Barluenga and F. Hernández-Olivares, "SBR latex modified mortar rheology and mechanical behaviour," Cement and Concrete Research, vol. 34, no. 3, pp. 527-535, 2004.

[22] H. I. Al-Abdul Wahhab, M. G. Baig, I. A. Mahmoud, and H. M. Kattan, "Study of road bases construction in Saudi Arabia using foam asphalt," Construction and Building Materials, vol. 26, no. 1, pp. 113-121, 2012.

[23] A. Behiry, "Utilization of cement treated recycled concrete aggregates as base or subbase layer in Egypt," Ain Shams Engineering Journal, vol. 4, no. 4, pp. 661-673, 2013.

[24] M. Pasetto and N. Baldo, "Experimental evaluation of high performance base course and road base asphalt concrete with electric arc furnace steel slags," Journal of Hazardous Materials, vol. 181, no. 1-3, pp. 938-948, 2010.

[25] J. L. Daniels, H. I. Inyang, and I. K. Iskandar, "Durability of Boston blue clay in waste containment applications," Journal of Materials in Civil Engineering, vol. 15, no. 2, pp. 144-152, 2003.

[26] O. Pospíchal, B. Kucharczyková, P. Misák et al., "Freezethaw resistance of concrete with porous aggregate," Procedia Engineering, vol. 2, no. 1, pp. 521-529, 2010.

[27] B. Kucharczyková, Z. Keršner, O. Pospíchal, P. Misák, P. Daněk, and P. Schmid, "The porous aggregate pre-soaking in relation to the freeze-thaw resistance of lightweight aggregate concrete," Construction and Building Materials, vol. 30, pp. 761-766, 2012.

[28] S. Bin-Shafique, K. Rahman, M. Yaykiran, and I. Azfar, "The long-term performance of two fly ash stabilized fine-grained soil subbases," Resources, Conservation and Recycling, vol. 54, no. 10, pp. 666-672, 2010.

[29] J. Liu, T. Wang, and Y. Tian, "Experimental study of the dynamic properties of cement- and lime-modified clay soils subjected to freeze-thaw cycles," Cold Regions Science and Technology, vol. 61, no. 1, pp. 29-33, 2010.

[30] B. D. Alkire and J. Jashimuddin, "Changes in strength of silt due to freeze-thaw," Journal of Technical Topics in Civil Engineering, vol. 110, no. 1, pp. 48-53, 1984.

[31] E. Simonsen and U. Isacsson, "Soil behavior during freezing and thawing using variable and constant confining pressure triaxial tests," Canadian Geotechnical Journal, vol. 38, no. 4, pp. 863-875, 2001.
[32] K. Hazirbaba and H. Gullu, "California bearing ratio improvement and freeze-thaw performance of fine-grained soils treated with geofiber and synthetic fluid," Cold Regions Science and Technology, vol. 63, no. 1-2, pp. 50-60, 2010. 

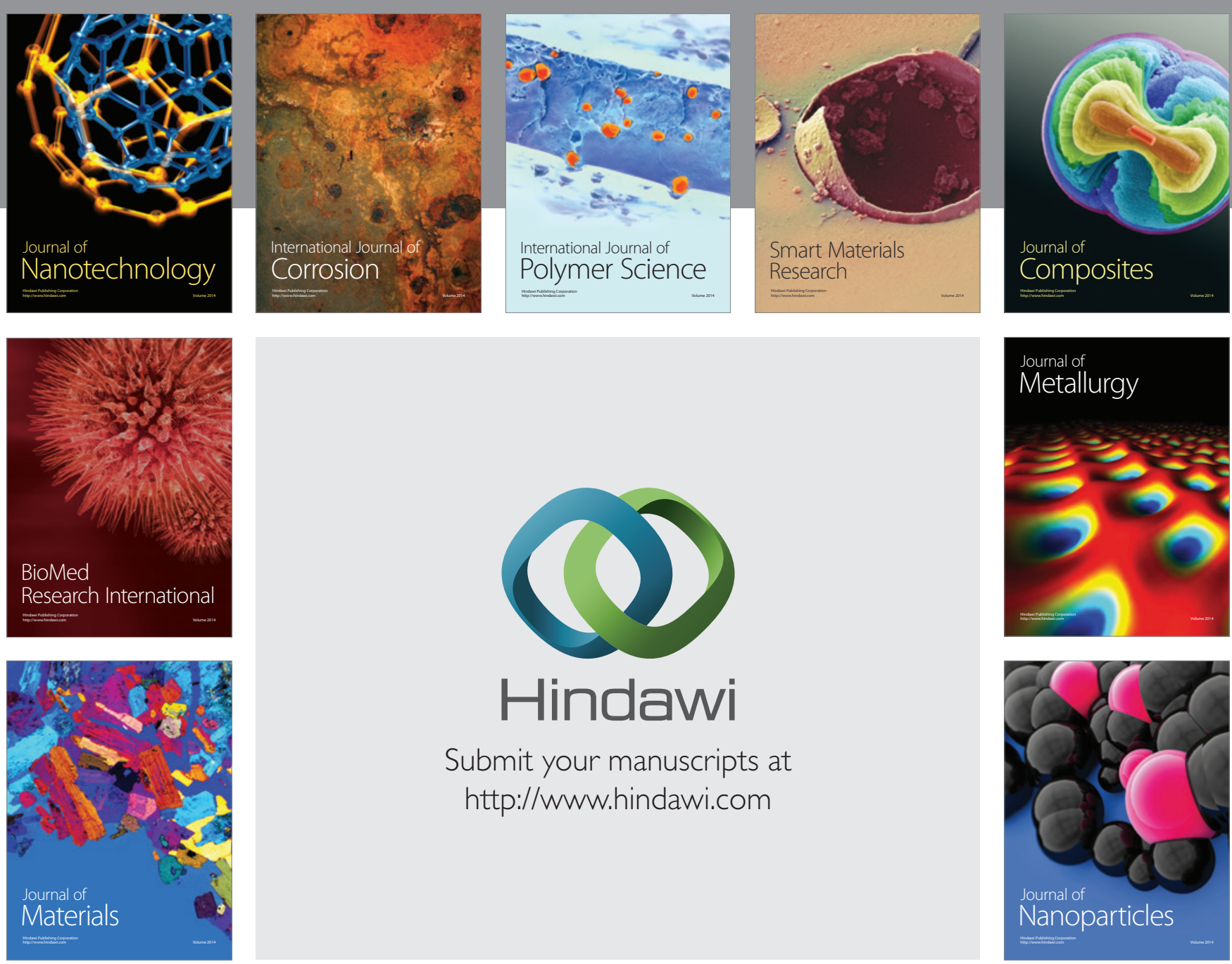

Submit your manuscripts at http://www.hindawi.com
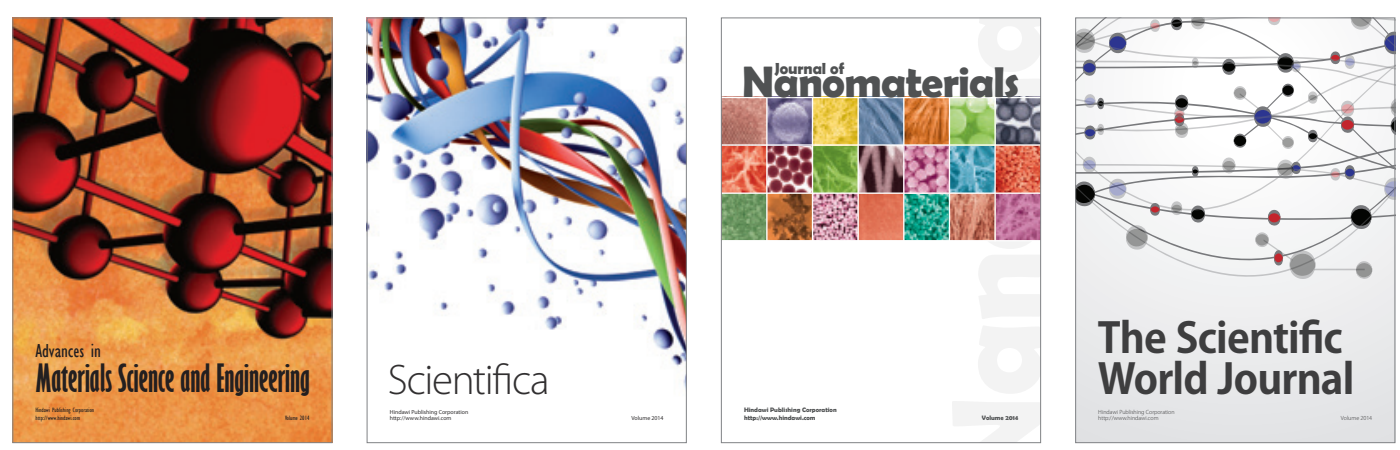

\section{The Scientific World Journal}
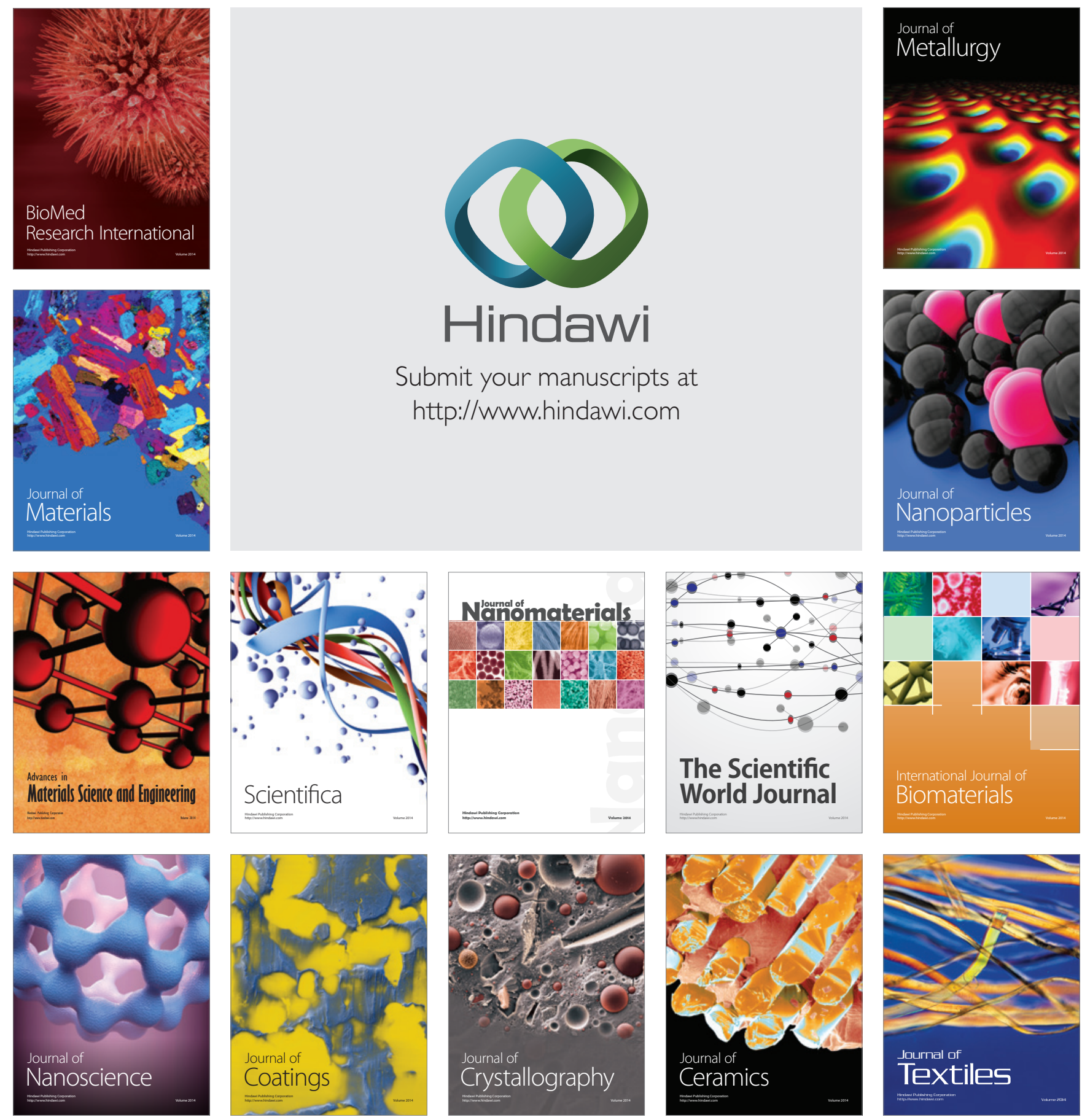